\title{
VARIAÇÃO NA PRODUÇÃO/APAGAMENTO DA VIBRANTE PÓS- VOCÁLICA NO FALAR FLORIANOPOLITANO
}

\author{
VARIATION IN THE PRODUCTION/DELETION OF POST-VOCALIC $/ \mathrm{r} / \mathrm{BY}$ \\ PORTUGUESE BRAZILIAN SPEAKERS FROM FLORIANÓPOLIS
}

\author{
Mariane Antero Alves \\ Doutoranda na Universidade Federal de Santa Catarina \\ mariantero@gmail.com
}

\begin{abstract}
RESUMO: O presente estudo trata do apagamento da vibrante pós-vocálica / $\mathrm{r} /$ na fala de oito informantes florianopolitanos, descendentes de açorianos, estratificados por idade, sexo, escolaridade e localidade. Foram também investigados contextos linguísticos que podem favorecer o apagamento do segmento em análise. $\mathrm{O}$ embasamento teórico para a pesquisa e coleta de dados está pautado na sociolinguística laboviana. Os resultados apontaram para maior apagamento do segmento /r/ quando este está inserido em final de palavra, quando assume função morfêmica, quando está na sílaba tônica e aparece diante de vogais anteriores. Com relação aos contextos extralinguísticos, os resultados mostraram maior apagamento na fala de informantes menos escolarizados, mais velhos, do sexo feminino e que moram em região menos urbana.
\end{abstract}

PALAVRAS-CHAVE: Vibrante pós-vocálica. Apagamento. Sociolinguística laboviana.

ABSTRACT: This study aims at investigating the post-vocalic / $r$ through speech samples from eight subjects from Florianópolis, divided according to age, gender, educational level and place. Linguistic contexts that might influence the deletion of the post-vocalic / $r /$ were also investigated. The theoretical background for this study is based on the Labovian Sociolinguistics. The results pointed out that the deletion of $/ r /$ prevailed in word-final position; when it functions as a morpheme; in stressed syllables; and when followed by front vowels. In relation to the geographical and social contexts, the results showed that there is more /r/ deletion in the speech of subjects: who were older; with less schooling; females; and who were from the countryside.

KEYWORDS: Post-vocalic /r/. Segment deletion. Labovian Sociolinguistics. 


\section{INTRODUÇÃO}

A vibrante é um fonema com marcante presença nas línguas, aparecendo em cerca de 75\% delas (LINDAU, 1985 apud MONARETTO, 1997). No português brasiliero (doravante PB), esse fonema pode ocorrer em diferentes posições na sílaba e pode ser realizado com diferentes tipos de variantes.

Do ponto de vista fonotático da língua portuguesa, o /r/ pode ocupar posição de ataque silábico como em "rato" (em início de palavra) e "cara" (intervocálico) ou ainda em coda silábica, como em "perda" (posição medial) e "falar" (posição final de palavra).

Com relação a aspectos fonético-fonológicos, o seu status é amplamente debatido na literatura. Monaretto $(1992 ; 1997)$ defende a visão de que o /r/ fraco (ou tepe) é o único fonema vibrante presente no $\mathrm{PB}$, sendo que a representação gráfica do $/ \mathrm{r}$ / no par mínimo "torra" e "tora", por exemplo, é feita pela presença de dois r-fracos (geminação) em "torra" versus um r-fraco em "tora". Já para Câmara Jr., o PB apresenta duas vibrantes, sendo a versão forte /r/ e a branda /r'/ (CÂMARA JR., 2009). Em coda silábica, no entanto, pode-se perceber diferentes realizações do arquifonema /R/, sendo que agora a distinção entre uma produção ou outra não é mais fonológica, como no caso dos "erres" fraco ou forte, mas sim apenas um caso de alofonia.

Segundo Seara et al. (2011), a alofonia existente na produção do /R/ pode ser observada através de sua realização como um tepe ou vibrante simples [ $\mathrm{r}$, como vibrante múltipla $[r]$, retroflexa $[r]$, fricativa velar surda $[x]$ ou sonora $[\gamma]$, e ainda fricativa glotal surda $[\mathrm{h}]$ ou sonora $[\mathrm{h}]$. Em coda silábica, destaca-se ainda o fenômeno de apagamento da vibrante que, de acordo com Monaretto (2000), parece ocorrer desde muito cedo e está em ampla difusão nas mais variadas regiões do Brasil, segundo resultados de pesquisas sobre o tema (VOTRE, 1978; CALLOU, MORAES, LEITE, 1995; SKEETE; 1996; MONARETTO, 1997; 2000; 2002).

Partindo do ponto de vista de que há variação na produção do /r/ em coda silábica, como atestado pelos autores supracitados, este estudo tem como objetivo investigar a variação entre a produção e o apagamento de $/ \mathrm{r} / \mathrm{em}$ posição de coda silábica (posição medial e final), sob o ponto de vista da sociolinguística quantitativa e da fonética acústica. Para tal fim, a fala de oito informantes, descendentes de açorianos e residentes em duas localidades de Florianópolis (regiões continental e insular) foi coletada e investigada de acordo com os pressupostos teórico-metodológicos da Teoria de Variação e Mudança, propostos por Labov (2008 [1972]). Para análise dos dados, utilizou-se o software Praat (BOERSMA; WEENIK, 2012) para que a análise acústica de formato de onda e de espectrograma fosse conduzida. Dessa maneira, a pesquisadora pode avaliar com mais eficácia (além da análise oitiva) a possível presença ou deleção do segmento-alvo.

A seção seguinte trará um breve resumo das teorias utilizadas como suporte para a pesquisa. Na Seção 3, a metodologia utilizada para coleta e análise dos dados será relatada e, na Seção 4, apresentar-se-á a análise dos dados coletados. Por fim, a Seção 5 trará as conclusões. 


\section{A VIBRANTE}

\subsection{Caracterização acústico-articulatória da vibrante}

As vibrantes do $\mathrm{PB}$, também conhecidas como "róticos", são segmentos pertencentes à classe das consoantes líquidas, juntamente com os segmentos laterais. Elas podem ser produzidas em diferentes regiões do trato oral. Na região alveolar, temos a produção de dois segmentos vibrantes, a vibrante simples $/ \mathrm{f} / \mathrm{e}$ a vibrante múltipla /r/. A diferença articulatória entre elas se dá pela quantidade de batidas da língua (articulador ativo) nos alvéolos (articulador passivo), que é geralmente única no caso da vibrante simples, e múltipla, como o próprio nome sugere, no caso da vibrante múltipla. Esses dois segmentos assumem status de fonema, já que fazem a distinção, por exemplo, do par mínimo "mirra" e "mira" (CRISTÓFARO-SILVA, 2007; SEARA et al., 2011).

Contudo, o PB apresenta diversificadas realizações do segmento rótico quando em coda silábica. Nesse ambiente, o rótico é considerado arquifonema /R/, já que a variação na sua realização não irá mais indicar mudança de significado. É o caso da palavra "dor", que pode ser realizada como ['dox], ['dor], ['doh], ['dor], ['dor], sem prejuízo ou mudança no significado. A partir desses exemplos, pode-se perceber que não só segmentos ditos líquidos podem ser produzidos como alofones de $/ \mathrm{R} /$, mas também segmentos fricativos, como em ['dox] e ['doh], quando /R/ tem como realização fonética uma fricativa velar surda e uma fricativa glotal surda, respectivamente. $\mathrm{O}$ presente estudo concentrará suas análises na produção ou apagamento da vibrante $/ \mathrm{r} /$.

Além da alofonia existente para /R/, que confere diferentes peculiaridades aos dialetos do PB, alguns estudos como os de Votre (1978), Monguilhott (1997) e Monaretto $(2000 ; 2002)$ apontam para a não realização do segmento rótico em final de sílaba, representado por [ø], que pode ocorrer tanto em meio quanto em final de palavra, tendo a vibrante função morfêmica ou não. $\mathrm{O}$ apagamento do rótico em final de sílaba não parece estar relacionado a um determinado dialeto, pois foi encontrado em diferentes regiões do país, como por exemplo, no Rio de Janeiro por Votre (1978), na Região Sul por Monaretto (2000; 2002), em João Pessoa por Skeete (1996) e Salvador por Callou, Moraes e Leite (1996).

Segundo Hora, Pedrosa e Cardoso (2010), uma possível explicação para a ampla variação que ocorre na produção do /r/ é que

pelo fato de a coda ser a posição mais débil da estrutura silábica (SELKIRK, 1982), a variação que permeia os segmentos que a preenchem, seja na posição interna ou final, é muito comum no PB, conforme comprovado pelos diversos estudos sociolinguísticos até então realizados (2010, p.72).

Além disso, esses autores ainda mencionam que a preferência quase que universal das línguas pelo padrão silábico $\mathrm{CV}$ pode explicar o fenômeno do apagamento 
de /r/ em coda silábica (como, por exemplo, na palavra "falar", pronunciada como [fa'la]).

Com relação ao apagamento da vibrante em posição medial e final de sílaba, estudos como os de Monaretto (2000) e Hora e Monaretto (2003) atestam uma maior taxa de queda em posição final. Hora, Pedrosa e Cardoso (2010) afirmarm que os segmentos róticos em posição final estão mais propícios ao apagamento, pois estão inseridos em regiões mais fracas da sílaba.

\subsection{A vibrante sob a ótica da Teoria da Variação e Mudança}

De acordo com a teoria laboviana, a variação é um fenômeno inerente às línguas do mundo, mas não se configura como um fenômeno que ocorre de maneira livre. Esse fenômeno, segundo Labov (2008 [1972]), acontece de maneira ordenada e sistematizada, evidenciando que os sistemas linguísticos são heterogêneos.

O interesse central da Teoria da Variação e Mudança é a investigação da fala que, apesar de individual, pode apontar tendências que indicam certos movimentos na língua rumo à mudança, ou simplesmente fenômenos linguísticos variáveis que podem ser influenciados por fatores linguísticos e sociais. Em estudos que seguem essa perspectiva teórica, os dados de fala costumam ser extraídos de entrevistas sociolinguísticas - a entrevista laboviana. Os dados nesse tipo de entrevista devem ser coletados em situações reais com perguntas que suscitem a fala espontânea, ou seja, aquela de onde é possível se extrair o vernáculo.

Como relatado anteriormente, a vibrante /r/ é um dos segmentos que está em ampla variação no PB, sendo que é em posição de coda (medial ou final) que se observa a maior diversidade de variantes na sua produção, constituindo-se, nessa posição, um caso de alofonia.

Brescancini e Monaretto (2008) traçam um panorama através de resultados obtidos com trabalhos que analisaram amostras de fala do banco de dados Varsul de Santa Catarina e Rio Grande do Sul. Com relação ao apagamento da vibrante em coda silábica, as autoras chamam atenção para quatro trabalhos: Monguillhot (1997), que estuda a fala das quatro cidades catarinenses disponíveis no Varsul (Florianópolis, Lages, Blumenau e Chapecó); Monaretto (2000), que analisa os dados das três capitais sulinas também do mesmo banco (Florianópolis, Porto Alegre e Curitiba); Gregis (2001), que investiga a fala de Porto Alegre do banco Varsul, e Pimentel (2002), que, apesar de não utilizar esse banco de dados, valeu-se de procedimentos metodológicos similares para a coleta de entrevistas na capital gaúcha. Brescancini e Monaretto (2008) observam, através desses quatro estudos, que o apagamento da vibrante em coda silábica parece ocorrer da seguinte forma:

Com base em amostra de 800 ocorrências, Monguillhot (1997), [...], obtém $71 \%$ de aplicação da regra de apagamento para as cidades que compõem a amostra catarinense do Varsul. Ao considerar as capitais dos três estados sulinos, Monaretto (2000) obtém 40\% de aplicação. Os resultados para Porto Alegre de Gregis (2001) e Pimentel (2002) apontam para os valores de 49,5\% e $37 \%$, respectivamente. (BRESCANCINI; MONARETO, 2008, p.60). 
Pode-se observar a grande variação que parece ocorrer entre o apagamento e a realização dentro da variável dependente da 'produção da vibrante coda silábica' no português falado no sul do Brasil. Cabe ainda ressaltar que, para os quatro estudos analisados por Brescancini e Monaretto (2008), as variáveis independentes que se mostraram favoráveis ao apagamento em todos eles foram 'classe morfológica verbo' e 'posição final', variáveis estas de caráter linguístico. A variável 'função morfêmica' mostrou relevância em favor do apagamento nos estudos de Monaretto (2000) e Pimentel (2002) - sendo que essa variável não foi considerada nos dois outros trabalhos analisados pelas autoras.

Com relação ao contexto vocálico precedente, as autoras relatam que Monaretto (2000) aponta que há influência da vogal [a] sobre o apagamento, e Monguilhott (1997) mostra que a vogal [e] é que exerce maior influência sobre o apagamento da vibrante. Ambos os estudos indicam, então, que as vogais anteriores parecem exercer maior influência sobre o apagamento da vibrante.

Os quatro estudos analisados por Brescancini e Monaretto (2008) levam em consideração a variável tonicidade. Contudo, apenas Pimentel (2002) aponta a tonicidade - sílaba tônica como contexto favorecedor do apagamento.

Quanto às variáveis sociais, apenas Monaretto (2000) e Monguilhott (1997) examinaram a influência da escolaridade no apagamento e constataram que ele acontece mais em indivíduos com baixa escolaridade.

Dentre os quatro trabalhos, são concordantes em relação à variável "faixa etária" os de Monaretto (2000) e Pimentel (2002), que observam que os jovens tendem a produzir mais apagamento, o que pode atestar a mudança em curso.

A variável "sexo" só se mostra relevante em relação ao apagamento no estudo de Monguilhot (1997) - sexo masculino - e em Gregis (2001) - sexo feminino, sendo que os outros estudos não computaram essa variável.

Por fim, a localidade Florianópolis despontou como a que mais produz apagamento dentre as investigadas por Monguilhott (1997) - em relação às outras cidades do Varsul de Santa Catarina e por Monaretto (2000), em relação às outras duas capitais sulinas.

Apesar da ampla variação entre realização e apagamento da vibrante pósvocálica mostrada por Brescancini e Monaretto (2008), esse não é um fenômeno que se restringe somente à Região Sul do Brasil. Investigações como as de Votre (1978), Callou, Moraes e Leite (1996) e Skeete (1996) também apontam a presença da regra variável em diversas regiões do país.

No trabalho de Votre (1978 apud Monguilhott, 2007), ao estudar a fala carioca de alfabetizandos e universitários, o autor pôde constatar que a variável sociolínguística "escolaridade" influencia a realização do $/ \mathrm{r} /$, sendo que universitários tendem a preservá-la. Em relação aos contextos linguísticos, Votre notou que há um favorecimento do apagamento quando o /r/ assume função morfêmica.

Já Callou, Moraes, Leite (1996 apud Monguilhott, 2007) investigaram a fala em cinco capitais brasileiras (Porto Alegre, São Paulo, Recife, Salvador e Rio de Janeiro) a 
partir de uma amostra do corpus Nurc. Os resultados mostraram que, tanto em Porto Alegre quanto em São Paulo, a queda do [r] final é favorecida pela vogal anterior [a]. No Rio de Janeiro, há uma variação estável entre apagamento e permanência desse segmento, enquanto que em Salvador há uma evidência de mudança em favor do apagamento de [r] pós-vocálico. Os autores verificaram também que há uma preferência pelo uso da fricativa no Rio de Janeiro e em Salvador, e do tepe em São Paulo, Porto Alegue e Recife quando o [r] é mantido.

Nos dados de João Pessoa, Skeete (1996 apud Monaretto, 1997) observa que o apagamento está em processo acelerado de implementação, especialmente se for levada em consideração a variável "escolaridade", sendo ela motivadora da permanência desse segmento nos dados analisados por esse estudo.

Observando-se os resultados dos trabalhos supracitados, pode-se perceber que o processo de apagamento da vibrante pós-vocálica está em ampla implementação no PB, especialmente quando esse segmento encontra-se em contexto de final de palavra e assume função morfêmica. Com relação aos contextos extralinguísticos, o que mais chama atenção é a tendência de manutenção de /r/ pós-vocálico por informantes mais escolarizados, o que pode indicar que essa é a variante de maior prestígio.

Levando esses fatos em consideração, o presente estudo pretende analisar os dados coletados em Florianópolis, a partir da fala de descendentes de açorianos, para investigar o fenômeno do apagamento da vibrante pós-vocálica.

\section{METODOLOGIA}

Os dados coletados para a presente pesquisa foram extraídos da amostra intitulada Floripa. Essa amostra foi montada a partir da gravação de entrevistas sociolinguísticas em diferentes pontos da cidade de Florianópolis ${ }^{1}$.

A amostra Floripa seguiu alguns critérios de organização, dentre eles:

(1) Os participantes deveriam ser nascidos e criados nas localidades selecionadas ${ }^{2}$, podendo ter residido, no máximo, por dois anos fora da comunidade;

(2) Todos deveriam ser filhos de descendentes de açorianos e os pais e avós deveriam ser da própria localidade ou arredores da cidade.

Além dos critérios acima, os participantes foram organizados em diferentes células sociolinguísticas, de acordo com sexo, idade, escolaridade e localidade. Nossos informantes, portanto, estão divididos em duas faixas etárias: a faixa "jovem” que

\footnotetext{
${ }^{1}$ Os dados foram coletados por alunos da disciplina e Sociolinguística e Dialetologia, do curso de PósGraduação em Linguística, ministrada pelos professores Edair Gorski, Felício Margotti e Izete Coelho, no primeiro semestre de 2012.

${ }^{2}$ As localidades selecionadas para coleta foram Ingleses, Coqueiros, Centro/Trindade, Ribeirão da Ilha, Santo Antônio de Lisboa/Ratones e Costa da Lagoa.
} 
compreende quatro informantes com idade entre 15-40 anos e a faixa "+velho", com quatro informantes com idade acima de cinquenta anos.

Com relação ao grau de escolaridade, os informantes foram separados em duas categorias: "menos escolarizados", com quatro informantes que possuiam até oito anos de escolarização; e "mais escolarizados", com quatro informantes que haviam concluído ou estavam cursando o ensino superior.

Apesar de a amostra Floripa disponibilizar seis localidades, nós optamos por trabalhar com apenas duas, sendo Coqueiros (na região continental) e Ribeirão da Ilha (região insular), com quatro informantes de cada região. Das seis localidades do banco Floripa em que foram realizadas as entrevistas, optamos por investigar uma região classificada como "mais urbano" (Coqueiros) e um bairro "menos urbano" (Ribeirão da Ilha).

Em relação à variável "sexo", contamos com dados de fala de quatro informantes do sexo masculino e quatro informantes do sexo feminino.

Assim, temos como variável dependente 'a produção do /r/ pós-vocálico' que, de acordo com Monguilhott (1997) e Monaretto (2000), ocorre em Florianópolis preferenciamente através da fricativa velar $[\mathrm{x}]$ e do apagamento do mesmo segmento. Como variáveis independentes, elegemos os grupos de fatores linguísticos - 'posição da vibrante na palavra' (medial $x$ final), 'função da vibrante' (morfêmica $x$ nãomorfêmica), 'contexto seguinte' (pausa, consoante ou vogal), 'acento lexical' (se a vibrante está em sílaba tônica ou átona), 'dimensão da palavra' (monossílabo, dissílabo, ou polissílabo), 'vogal anterior' ([a], [e], [e], [i], [o], [o] e [u]) - e os grupos de fatores extralinguísticos - 'sexo', 'idade' (15-40 e acima de 50), 'escolaridade' (até oito anos e ensino superior) e localidade (Coqueiros e Ribeirão da Ilha).

As entrevistas foram gravadas em diferentes equipamentos de capitação de som tais como gravadores de som, softwares e microfones. Todas as gravações foram feitas in loco, isto é, na própria comunidade.

No que tange à etiquetagem dos dados, podemos ressaltar que ela foi feita manualmente com a ajuda da análise espectrográfica através do software Praat (BOERSMA; WEENIK, 2012), para que a pesquisadora pudesse melhor visualizar as ocorrências e utilizar-se desse artifício na decisão pela presença ou não do /r/ no dado de fala. A Figura 1 ilustra um dado referente à palavra "parteira", em que houve produção do [r]. 
Figura 1 - Exemplo extraído da amostra Floripa: palavra "parteira" com manutenção do [r], pronunciada como [pax'tera].

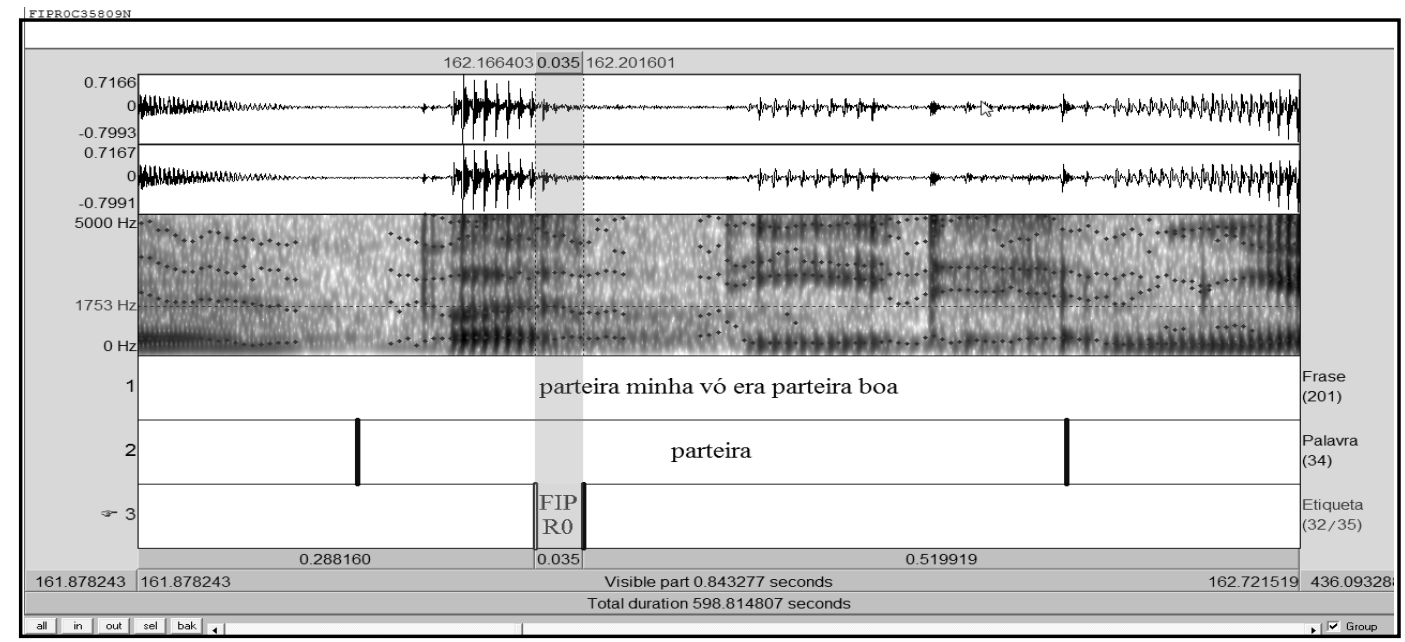

Pode-se observar na Figura 1 a presença de uma área destacada. Essa região corresponde ao segmento [r]. A primeira linha logo abaixo do espectrograma (frequência $v s$. tempo) apresenta a transcrição ortográfica da frase - utilizada para se observar o contexto seguinte à palavra onde o /r/ está inserido. $\mathrm{Na}$ linha seguinte podese observar a transcrição da palavra e, por último, a etiqueta apresentando os índices utilizados para a análise. O Quadro 1 apresenta a descrição dos índices utilizados na etiquetagem dos dados, correspondentes às variáveis controladas.

Quadro 1 - Índices utilizados na etiquetagem dos dados, com as respectivas variáveis.

\begin{tabular}{|c|c|c|}
\hline & Variável & Índice \\
\hline \multirow{3}{*}{ Váriaveis Extralinguísticas } & Sexo & (F) feminino ; (M) masculino \\
\hline & Idade & (J) jovem; (V) +velho \\
\hline & Escolaridade & (P) Até 8 anos ; (S) Superior \\
\hline \multirow{6}{*}{ Váriaveis Linguísticas } & Posição na palavra & (0) medial ; (1) final \\
\hline & Função & (2) morfêmica ; (3) fonêmica \\
\hline & Tonicidade & (4) sil. tônica ; (5) sil. átona \\
\hline & Tipo de palavra & (6) mono ; (7) di ; (8) polissílabo \\
\hline & Vogal precedente & $\begin{array}{l}(09)[\mathrm{a}] ;(10)[\mathrm{e}] ;(11)[\mathrm{i}] ;(12) \\
{[\varepsilon] ;(13)[\mathrm{o}] ;(14)[\mathrm{o}] ;(15)[\mathrm{u}]}\end{array}$ \\
\hline & Contexto seguinte & (C) consoante ; $(\mathrm{V})$ vogal \\
\hline
\end{tabular}

Ressalta-se ainda que, nos casos em que a palavra seguinte ao [r] final era iniciada por uma vogal, dois fenômenos foram observados: (i) o fenômeno de sândi externo, quando o [r] (na maioria dos casos, fricativo) se transforma em tepe, a 
exemplo: "por aqui", em que ao invés da pronúncia ['pox a'ki] temos [pora'ki]; e (ii) o fenômeno de apagamento, quando, por exemplo, em "estudar e", ao invés da pronúncia

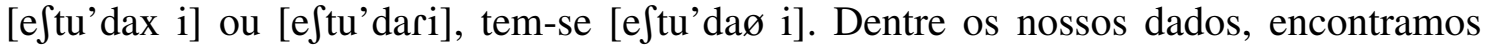
apenas 18 em que ocorreu o primeiro processo. Optamos, então, por excluir esse tipo de dado, que não era relevante para análise.

Os dados foram organizados em tabelas para cada um dos informantes, o que facilitou a sua manipulação e inserção no software estatístico, para que as rodadas estatísticas pudessem ser realizadas. Para isso, utilizamos o software GoldVarb. Contudo, nossa análise irá restringirá aos resultados percentuais (frequência de ocorrência) fornecidos pelo programa estatístico.

\section{PERGUNTAS DE PESQUISA E HIPÓTESES}

As perguntas de pesquisa e hipóteses formuladas abaixo nortearam a investigação da presente pesquisa.

Em termos gerais, ocorrerá mais apagamento ou manutenção do /r/ na fala dos sujeitos investigados?

Hipótese 1: Com base em Monguilhott (1997) e Monaretto (2000), prevemos que haverá uma maior taxa de ocorrência de apagamento da vibrante pós-vocálica.

Qual a influência dos contextos linguísticos investigados no apagamento da vibrante pós-vocálica?

Hipótese 2: A partir do trabalho de Votre (1978) e dos relatos de Brescancini e Monaretto (2008), acreditamos que os contextos que mais se destacarão em favor do apagamento são 'função morfêmica' e 'posição final na palavra'. Com relação ao acento lexical, esperamos que a sílaba tônica possa favorecer o apagamento, pois, na maioria dos casos, a sílaba tônica recai sobre a posição final, onde $\mathrm{o} / \mathrm{r} /$ assume a função morfêmica (PIMENTEL, 2002). Já para as vogais precedentes, supomos que as vogais anteriores irão favorecer o apagamento, de acordo com os achados de Monguilhott (1997) e Monaretto (2000). Por fim, com relação ao contexto seguinte, acreditamos que a presença de consoante será um fator condicionante em favor do apagamento da vibrante.

Como se dá a influência dos grupos de fatores extralinguísticos localidade, escolaridade, idade e sexo na produção e no apagamento de $/ \mathrm{r} /$ ?

Hipótese 3: Também de acordo com os resultados de Votre (1978), Monguilhott (1997), Monaretto (2000) e Skeete (1996), acreditamos que a variável escolaridade irá influenciar a produção da vibrante $/ \mathrm{r} /$, sendo que falantes menos escolarizados tenderão a uma maior taxa de apagamento, enquanto que falantes mais escolarizados à manutenção da vibrante. Já com relação às outras variáveis, vimos que há divergência nos estudos que analisam esses fatores e, portanto, não conseguimos prever como os resultados irão se apresentar. 


\section{DESCRIÇÃO E ANÁLISE DE DADOS}

$\mathrm{Na}$ tentativa de facilitar a leitura e compreensão dos resultados, nossa análise será conduzida através da busca de respostas para as perguntas e hipóteses lançadas na seção 4.

A primeira pergunta de pesquisa questiona se haverá mais apagamento ou manutenção do /r/ dentre os dados. Segundo os resultados obtidos através do GoldVarb, do total de 543 dados de /r/ pós-vocálico coletados, houve 307 ocorrências $(56,5 \%)$ de pagamento de /r/ e 236 ocorrências $(43,5 \%)$ de manutenção do /r/. Desse modo, a Hipótese 1 foi confirmada. Apesar da pouca diferença entre os dados de apagamento e manutenção, houve uma preferência pelo apagamento. Esse resultado corrobora os achados de Monguilhott (1997), que encontrou um índice de 71\% de apagamento para dados coletados em situações similares às nossas, dados que incluíam a cidade de Florianópolis.

A segunda pergunta de pesquisa questiona a influência dos fatores linguísticos sobre o apagamento da vibrante /r/ pós-vocálica. Vamos delinear a influência de cada variável separadamente.

Primeiramente, os estudos sobre o tema parecem convergir para o fato de que a função morfêmica favorece o apagamento do /r/, conforme citado anteriormente. Os nossos dados atestam esse fato, pois encontramos uma taxa de 96,5\% favorável ao apagamento nos dados em que a vibrante assume função morfêmica. Na função nãomorfêmica, o /r/ é apagado em apenas 28,1\% dos casos. Esse resultado pode estar relacionado, segundo Monaretto (2000), ao fato de que verbos (estejam eles na primeira ou terceira pessoa do subjuntivo, ou ainda no infinitivo) são marcados, com redundância, pelo acento lexical (que recai sobre a última sílaba) e pela presença do [-r] morfêmico. Ainda segundo a autora, o apagamento em outros tipos de palavras é mais restrito, pois nem todas são acentuadas na sílaba que contém o /r/ final. Outra questão interessante levantada por Monaretto (2000) é que, dentre as três capitais sulinas investigadas em seu estudo, Florianópolis foi aquela que mais apresentou queda do $/ \mathrm{r} /$ em função morfêmica, o que mostra "o estágio final do processo de enfraquecimento que a vibrante vem sofrendo nessa região, o que se justifica pelo fato de os informantes dessa localidade preferirem a articulação posterior da vibrante" (p. 280). Esse resultado é corroborado pela alta taxa de apagamento encontrada em nossos dados para a vibrante em função morfêmica. Nos dados onde houve manutenção do /r/, também observamos a preferência pela variante fricativa velar. Cabe ressaltar que, em nossa amostra, foram incluídos na categoria "morfêmicos" dados em que a vibrante aparece em verbos finalizados por [-ar], [-er], [-ir], [-or] e quando ela faz parte do morfema, como em "pescad[-or]" ou "profess[-or]".

Com relação à posição que a vibrante ocupa na palavra, os resultados mostraram que de 270 dados em posição final, 86,3\% sofreram apagamento. Já quando a vibrante está posicionada no interior da palavra, dentre 273 dados, apenas 27,1\% apresentaram apagamento. Esses resultados vão ao encontro dos de Hora e Monaretto (2003), Hora, Pedrosa e Cardoso (2010), Monaretto (2000), Monguilhott (1997), Gregis (2001) e Pimentel (2002).

Hora, Pedrosa e Cardoso (2010) relatam que o apagamento tende a ser mais presente quando o rótico está em posição final, pois ela é mais "fraca" do que a medial, 
por estar no final do nível prosódico da palavra, favorecendo assim o apagamento. Com isso, a sílaba resultante se transforma no padrão (CV), que, segundo esses autores, é o padrão mais universal dentre as línguas. Por isso, existiria uma preferência por esse tipo silábico e o apagamento seria uma das formas de se evitar um padrão silábico mais complexo no PB.

Ainda segundo Hora, Pedrosa e Cardoso (2010), o apagamento em posição medial pode estar condicionado pela consoante que segue a vibrante, sendo o apagamento favorecido quando seguido de fricativa. Nos nossos resultados, verificamos que dentre todas as 47 ocorrências de vibrante seguida por segmento fricativo, 17 dados apresentaram apagamento $(36,2 \%)$. Para os 80 casos de vibrante seguida de segmentos nasais, obtivemos 18 dados com apagamento (29\%). Por fim, das 85 ocorrências de vibrante seguida de plosiva ${ }^{3}, 15$ dados apresentaram apagamento (17,6\%). Comparando-se os percentuais de apagamento, vemos que há uma tendência para o apagamento da vibrante sucedida por fricativa, corroborando os achados de Hora, Pedrosa e Cardoso (2010).

Um caso interessante que vale salientar são os resultados obtidos em relação à palavra "porquê". Esse vocábulo foi o que mais se destacou em número de ocorrências na amostra analisada, sendo 46 ocorrências em 543 dados (8,5\%). Verificamos um número bastante considerável de apagamento de /r/ nesse vocábulo, ou ainda casos em que não só o /r/ era apagado, mas também a vogal antecedente a ele, sendo encontradas produções como [pu'ke] ou ainda [p'ke]. Desses 46 casos de ocorrência de "porquê", em 24 deles $(57,14 \%)$ ocorreram apagamentos, apenas da vibrante ou da vibrante e da vogal precedente $[\mathrm{u}]$. Assim, devido ao considerável número de ocorrências e de apagamentos da vibrante nessa palavra, podemos inferir que a frequência do uso (BYBEE, 2001) pode estar influenciando esse apagamento, pois o /r/ está em contexto medial, que não é favorecedor do apagamento, como visto acima. Monaretto (2000) afirma que é comum, para palavras funcionais como "porquê" e "qualquer", o apagamento da vibrante, podendo ser até categórico para alguns informantes. Em nossos dados, verificamos que houve apagamento categórico na fala de dois informantes, mas devido ao pouco número de casos na produção de cada um, não podemos afirmar se essa tendência se manteria para um númeo maior de dados.

Analisando-se o contexto "acento lexical", observamos que /r/ inseridos em sílaba tônica foi apagado em $69,9 \%$ dos dados, corroborando os resultados de Pimentel (2002). Já o /r/ em sílabas átonas obteve uma taxa de 32,5\% de queda.

Com relação à vogal anterior, a Tabela 1 apresenta as taxas percentuais de apagamento da vibrante.

\footnotetext{
${ }^{3}$ Excluímos os dados referentes à palavra "porque", pois como relatado no parágrafo seguinte, pareceu ocorrer apagamento da vibrante nessa palavra pela grande frequência de ocorrência.
} 
Tabela 1 - Percentuais de queda e preservação de /r/ em relação às vogais precedentes

\begin{tabular}{|c|c|c|c|}
\hline & No. de dados & Apagamento de /r/ & Preservação de /r/ \\
\hline$[\mathrm{i}]$ & 41 & $65,9 \%$ & $34,1 \%$ \\
\hline$[\mathrm{a}]$ & 196 & $65,8 \%$ & $34,2 \%$ \\
\hline$[\mathrm{e}]$ & 157 & $59,2 \%$ & $40,8 \%$ \\
\hline$[\mathrm{u}]$ & 33 & $48,5 \%$ & $51,5 \%$ \\
\hline$[\mathrm{o}]$ & 76 & $42,1 \%$ & $57,9 \%$ \\
\hline$[\varepsilon]$ & 17 & $29,5 \%$ & $70,6 \%$ \\
\hline$[0]$ & 23 & $21,7 \%$ & $78,3 \%$ \\
\hline
\end{tabular}

Analisando a Tabela 1 podemos perceber que as vogais anteriores [i], [a] e [e] apresentaram percentuais maiores que $50 \%$ de apagamento da vibrante. Esse resultado reitera os achados de Monguilhott (1997) e Monaretto (2000), que apresentavam prevalência de apagamento para vogais anteriores.

Em relação à dimensão do vocábulo, nossos resultados apontam para maior apagamento quando a vibrante está inserida num vocábulo monossílabo com $75,8 \%$ de apagamento, seguida por vocábulo dissílabo, com $59,4 \%$ e por tri ou polissílabo, com $46,3 \%$.

Por fim, observamos que o contexto seguinte que mais favorece o apagamento é o contexto vocálico com $96,1 \%$, seguido por pausa $(84,3 \%)$ e contexto consonantal $(45,9 \%)$.

Podemos concluir que os resultados apontam para a confirmação da Hipótese 2, pois os resultados foram favoráveis ao apagamento tanto no contexto 'função morfêmica' quanto 'posição final na palavra', como previsto por essa hipótese.

Em se tratando da influência de variáveis extralinguísticas sobre o apagamento ou a realização de /r/, a Hipótese 3 prevê, de acordo com os estudos citados, que a variável "escolaridade" pode influenciar a produção da vibrante no sentido de que os informantes mais escolarizados iriam apresentar um índice mais elevado em favor da preservarção. Tal fato foi confirmado, pois a vibrante se manteve em 54,5\% dos dados desses informantes, enquanto os menos escolarizados apresentaram um índice de 48,6\% de manutenção. Esses resultados corroboram os achados de Votre (1978), Monguilhott (1997), Monaretto (2000) e Skeete (1996) e atestam a Hipótese 3, indicando que a variante de maior prestígio deve ser de maior a preservação de $/ \mathrm{r} /$.

Com relação aos outros contextos extralinguísticos, os resultados que encontramos na literatura apontavam para divergências entre os estudos, o que nos impossibilitava de fazer predições precisas.

Nossos resultados mostram que, com relação ao grupo de fatores "sexo", houve maior taxa de apagamento na produção das informantes femininas, com $61 \%$, contra $51 \%$ de apagamento nos informantes masculinos. Segundo Brescancini e Monaretto (2008), o sexo feminino é apontado nos estudos de sociolinguística como aquele que 
mais utiliza as variantes inovadoras, fato corroborado pelos nossos resultados. É interessante correlacionar esse resultado com os achados de alguns estudos nessa área que apontam que as mulheres são aquelas que tendem a usar a regra de maior prestígio que para o /r/ parece ser a variante 'realização'. Podemos, então, perceber que, no presente estudo, essa tendência não foi confirmada, pois as nossas informantes do sexo feminino deram preferência ao uso da variante inovadora 'apagamento'. Esses dois achados, o de que as mulheres tendem a usar a variante inovadora e que elas tendem a manter a variante de maior prestígio podem colaborar para a divergência encontrada entre os estudos que investigam 'sexo' como uma das variáveis controladas.

Já para a "idade", os resultados apontam para a prevalência do apagamento tanto para os informantes mais velhos como para os jovens, uma vez que ambos os grupos apresentaram mais de $50 \%$ de apagamento em sua produção $(60,1 \%$ e $51,5 \%$, respectivamente). Observando que os informantes mais velhos apresentaram um percentual levemente maior que os jovens, nossos dados apresentam uma tendência oposta aos resultados de Monaretto (2000) e Pimentel (2002), que encontraram maior apagamento entre os mais jovens. A primeira vista, esse resultado parece "retirar" da variante apagamento o status de "variante inovadora", visto que parece ser mais utilizada dentre os mais velhos. Contudo, não podemos esquecer que dentre os resultados dos informantes mais jovens, ela é a mais utilizada, pois $51,5 \%$ de $/ \mathrm{r} /$ pósvocálico foram apagados, mostrando, assim, a preferência dos jovens pela variante inovadora tanto quanto a preferência dos mais velhos.

Com relação às duas regiões controladas, vimos que há mais apagamento nos dados da localidade que foi considerada "menos urbana", o Ribeirão da Ilha, que apresentou apagamento em $65,2 \%$ dos resultados. A região de Coqueiros, considerada "mais urbana" apresentou apagamento em 46,4\%. As regiões mais urbanizadas, por permitirem um acesso mais facilitado à escolarização e também um maior contato linguístico, podem influenciar na preservação de variantes ditas de "maior prestígio" ou que indicam uma fala mais cuidada. Cabe ressaltar que o bairro do Riberão da Ilha conta com escolas públicas de educação básica e de nível médio. Além disso, a distância considerável até o centro da cidade, onde se concentra o maior número de escolas e universidades também deve ser considerada. Já o bairro de Coqueiros conta com escolas públicas, bem como um Instituto Federal de Educação e está localizado a menos de 10 minutos do centro da cidade, o que acaba facilitando o acesso às instituições de ensino.

\section{CONSIDERAÇÕES FINAIS}

Este estudo descreveu a vibrante em coda silábica /r/ através da fala de oito informantes de duas localidades de Florianópolis. Diferentes contextos linguísticos e extralinguísticos que podem influenciar a produção ou o apagamento desse segmento foram levados em consideração na análise.

Nossos resultados apontaram para uma maior frequência de apagamento de $/ \mathrm{r} /$, isto é, $56,5 \%$ de ocorrências em que não houve produção desse segmento em coda silábica. Sua posição em relação à palavra se mostrou relevante, já que $86,3 \%$ dos casos de $/ \mathrm{r} / \mathrm{em}$ final de palavra foram apagados. Em posição medial, não verificamos essa 
tendência (apenas 27,1\% de apagamento). Encontramos, portanto, um padrão diferenciado de comportamento do rótico em relação à posição medial e final. Além disso, em posição medial, o apagamento da vibrante parece ser favorecido quando este segmento encontra-se diante de fricativas.

Outro contexto em que ocorreu acentuada frequência de apagamento foi quando $\mathrm{o} / \mathrm{r} /$ assumiu função morfêmica, com uma taxa de apagamento de 97,3\%, podendo estar relacionado ao grande número de verbos terminados em $/ \mathrm{r} /$ no PB. Quando esse segmento assumiu função não-morfêmica, houve apagamento em apenas 28,8\% dos casos. Com relação à vogal antecedente, os resultados mostraram há mais apagamento quando a vibrante é antecedida por vogais altas. A posição 'tônica' também parece influenciar o apagamento de $/ \mathrm{r}$ /, visto que em $64,3 \%$ dos casos ocorreram apagamento nessa posição. Cabe lembrar que, na maior parte dos casos em que /r/ está na sílaba tônica, a palavra possivelmente é um verbo, onde ocorre um alto índice de apagamento, como apontado anteriormente.

Por fim, das variáveis linguísticas investigadas, o "contexto seguinte" e "tipo de palavra" tiveram comportamento semelhante, pois apresentaram dois fatores com mais de $50 \%$ de casos de apagamento. Para a variável "contexto seguinte", onde tínhamos três fatores, dois deles apresentaram mais casos de apagamento, sendo "vogal", com 96,1\% dos casos com apagamento e "pausa" com 84,3\%. O fator "consoante" obteve menos de $50 \%$ dos casos de apagamento $(45,9 \%)$. Para a variável "tipo de palavra", monossílabos e dissílabos apresentaram mais de $50 \%$ de casos de apagamento $(75,8 \%$ e $59,4 \%$, respectivamente), enquanto os polissílabos apresentaram 46,3\%.

Dentre os resultados das variáveis extralinguísticas, destacamos, primeiramente, a variável "escolaridade", que a exemplo de Votre (1978) e Monguilhott (1997) foi a que mais apresentou diferença entre os percentuais. O grupo "menos escolarizado" apresentou $67 \%$ de casos de apagamento e o grupo "mais escolarizado" apresentou 45,5\%. Com relação às variáveis "sexo" e "idade", ambos os grupos (feminino x masculino e mais jovem x mais velho) de cada variável apresentaram mais de $50 \%$ de casos de apagamento. Apesar de os informantes mais velhos apresentarem maior taxa de apagamento do que os mais jovens, os dois grupos apresentaram índices relevantes de apagamento, dando preferência pela variante inovadora. Por fim, o grupo de fatores "localidade" pareceu também exercer influência. A localidade dita "menos urbana", o Ribeirão da Ilha, apresentou maior número de casos de apagamento $(65,2 \%)$ enquanto que a localidade "mais urbana", Coqueiros, apresentou apagamento em 46,4\% das ocorrências. Esse fato pode estar ligado à tendência de preservação da variante de mais prestígio em meios mais urbanizados, e consequentemente, com acesso mais facilitado à educação.

Observando-se que, para a maioria das variáveis (linguísticas ou extralinguísticas), obtivemos taxas de apagamentos maiores que 50\%, podemos considerar que há uma tendência ao apagamento do segmento vibrante $/ \mathrm{r} /$ no falar florianopolitano, especialmente quando o /r/ encontra-se em final de palavra e quando ele assume função morfêmica. Visto que os nossos resultados de apagamento corroboraram achados de estudos anteriores sobre o mesmo objeto, podemos apontar para uma possível mudança que pode estar se implementando no PB. Apesar de que a 
variante de prestígio ainda se mantenha bem frequente no grupo mais escolarizado, quando o /r/ assume função morfêmica, o seu apagamento é quase categórico.

\section{REFERÊNCIAS}

BOERSMA, P.; WEENIK, D. Praat - doing phonetics by computer. (Versão 5.3). Amsterdã: University of Amsterdam, 2012.

BRESCANCINI, C.; MONARETTO, V. N. de O. Os róticos no sul do Brasil: panorama e generalizações. Signum: estudos linguísticos, Londrina, n.11/2, p.51-66, 2008.

BYBEE, J. Phonology and language use. Cambridge: Cambridge University Press, 2001.

CÂMARA JR., J. M. Estrutura da língua portuguesa. 42 ed. Petrópolis: Editora Vozes, 2009.

CALLOU, D.; MORAES, J.; LEITE, Y. Variação e diferenciação dialetal: a pronúncia do /r/ no português do Brasil. In: KOCH, Ingedore (Org.). Gramática do português falado. Campinas: UNICAMP, 1996. v. 6, p. 465-493.

CRISTÓFARO-SILVA, T. Fonética e fonologia do português - roteiro de estudos e guia de exercícios. São Paulo: Editora Contexto, 2007.

GREGIS, H. O apagamento da vibrante pós-vocálica em Porto Alegre. Dissertação de Mestrado. Porto Alegre: PUCRS, 2001.

HORA, D. da; PEDROSA, J. L. R.; CARDOSO, W. Status da consoante pós-vocálica no português brasileiro: coda ou onset com núcleo não preenchido foneticamente?. Letras de Hoje, v.45 (1), p.71-79, 2010.

HORA, D. da; MONARETTO, V. N. de O. Enfraquecimento e apagamento de róticos. In: HORA, D. da; COLLISCHONN, G. (Org.) Teoria linguística: fonologia e outros temas. João Pessoa: Editora Universitária da UFPB, 2003. p. 114-143.

LABOV, W. Padrões sociolinguísticos. São Paulo: Parábola Editorial, [1972] 2008.

LINDAU, M. The story of /r/. In: FROMKIN, V (org.). Phonetic Linguistics: Essays in Honor of Peter Ladefoged. New York: Academic Press, p. 157-168, 1985.

MONARETTO, V. N. de O. A vibrante: representação e análise sociolinguística. Dissertação de Mestrado. Porto Alegre: UFRGS, 1992.

Um reestudo da vibrante: análise variacionista e fonológica. Tese de Doutorado. Porto Alegre: UFRGS, 1997.

O apagamento da vibrante posvocálica nas capitais do sul do Brasil. Letras de Hoje, v.35, n.1, p.275-284, 2000.

MONGUILHOTT, I. O. S. A vibrante em final de palavra em Santa Catarina. In: Encontro do Círculo de Estudos Linguísticos do Sul, Anais do II CELSUL. Florianópolis, 1997. 
A variação na vibrante florianopolitana: um estudo sócio-geolinguístico. Revista da Abralin, v.6 (1), p.147-169, 2007.

PIMENTEL, R. M. A variação linguística do fonema $/ r /$ em posição pós-vocálica. Dissertação de Mestrado. Porto Alegre: PUCRS, 2002.

SEARA, I. C; NUNES, V.G.; LAZZAROTO-VOLCÃO, C. Fonética e fonologia do português. $2^{\mathrm{a}}$ ed. Florianópolis: LLV/CCE/UFSC, 2011.

SELKIRK, E. The syllable. In: HULST, H. van der; SMITH, N. The structure of phonological representations (Part II). Dordrecht: Foris, 1982.

SKEETE, N. A. O uso variável da vibrante na cidade de João Pessoa. Dissertação de Mestrado. João Pessoa: UFPB, 1996.

VOTRE, S. Variação fonológica no Rio de Janeiro. Tese de Doutorado. Rio de Janeiro: PUCRJ, 1978.

Data de submissão: 21/05/2013

Data de aceite: 07/11/2013 